\title{
PENINGKATAN SUMBER DAYA MANUSIA MELALUI INFORMASI DAN TEKNOLOGI PADA UMKM DI KECAMATAN SUKAJADI
}

\author{
Didin Saepudin', Bambang Susanto ${ }^{2}$, Erna Garnia ${ }^{3}$, R. Aryanti Ratnawati ${ }^{4}$, Fitria Lilyana ${ }^{5}$, \\ Rusmin Nuryadin $^{6}$, Wiwin Sukiati ${ }^{7}$, Yuli Nawangsasi ${ }^{8}$, Ae Suaesih ${ }^{9}$, Henda Hendawati ${ }^{10}$, \\ Nenny Hendajany ${ }^{11}$, Eva Rachmawati ${ }^{12}$, Ine Aprianti ${ }^{13}$, Bambang Rustandi ${ }^{14}$, Sri Wahyuni ${ }^{15}$, \\ Deden Rizal $^{16}$, Tiktik Sartika ${ }^{17}$, Wuri Handayani ${ }^{18}$ \\ $1,2,3,4,5,6,7,8,9,10,11,12,13,14,15,16,17,18$ Universitas Sangga Buana
}

${ }^{1}$ korespondensi : didin.saepudin@usbypkp.ac.id

\begin{abstract}
ABSTRAK
Kemampuan dan pengetahuan para wirausahawan tehadap ilmu manajemen keuangan sangat kurang, sehingga dalam pengelolaan bisnisnya mengalami hambatan. Terlihat dari pengelolaan keuangan yang masih menggunakan skala kecil, belum menggunakan sistem imformasi secara terintegrasi untuk mengelola keuangan yang lebih baik, belum banyak menggunakan teknologi di bidang pemasaran serta ketepatan sasaran yang dilakukan oleh para wirausaha, kekurangan ide untuk melakukan inovasi dari bahan baku yang sudah ada ataupun mencari ide/gagasan baru. Tujuannya memfasilitasi peningkatan kemampuan pengelolaan usaha (produksi, keuangan, pemasaran dan SDM) dan pemberdayaan ekonomi masyarakat melalui ekonomi kreatif. Metode yang digunakan berbentuk workshop dengan pelaksanaan kegiatan pada tanggal 11 September 2019. Pelaksanaan workshop bertempat di Universitas Sangga Buana. Adanya transfer pengetahuan dari akademisi dan atau praktisi dalam upaya membantu pemecahan permasalahan dalam membangun UMKM yang baru bergerak, bahkan yang sudah berjalan untuk dapat menciptakan wirausaha yang baru yang kompeten dengan keahlian jenis usahanya. Dengan adanya workshop dapat menjadikan bekal yang mumpuni untuk para UMKM dapat mengaplikasikannya langsung untuk melakukan usaha dengan berkelanjutan namun terdapat beberapa kendala yang masih harus dipecahkan.
\end{abstract}

Kata Kunci: SDM, Produksi, Keuangan, Pemasaran, UMKM.

\begin{abstract}
The ability and knowledge of entrepreneurs regarding financial management is very lacking, so that the management of their business experiences obstacles. It can be seen from the financial management that still uses a small scale, has not used an integrated information system to manage finances better, has not used much technology in the marketing sector and the accuracy of targeting is carried out by entrepreneurs, lacks ideas to innovate from existing raw materials or looking for new ideas / ideas. The goal is to facilitate increased business management capabilities (production, finance, marketing and human resources) and community economic empowerment through the creative economy. The method used was in the form of a workshop with the implementation of activities on September 11, 2019. The workshop was held at Sangga Buana University. There is a transfer of knowledge from academics and / or practitioners in an effort to help solve problems in building new MSMEs, even those already running, to be able to create competent new entrepreneurs with expertise in their type of business. With the workshop, it can make a qualified provision for MSMEs to apply it directly to do business in a sustainable manner, but there are several obstacles that still have to be resolved.
\end{abstract}

Keywords: Human Resources, Production, Finance, Marketing, UMKM.

\section{PENDAHULUAN}

Saat ini kemampuan dan pengetahuan para usaha kecil terhadap ilmu manajemen sangat kurang, khususnya di bidang keuangan. Meskipun kebanyakan para wirausahawan tersebut sudah menempuh pendidikan formal, namun tidak semua 
memiliki latar belakang manajemen.

Sehingga, dalam pengelolaan bisnis mereka sering kali mengalami hambatan.

Hal ini terlihat dari pengelolaan Manajemen keuangan dan akuntansi yang dilakukan masih terbatas dengan skala kecil. Selain itu, perkembangan teknologi informasi yang semakin maju harus dapat dikuasai oleh para usaha kecil agar dapat mengembangkan bisnisnya. Pengelolaan keuangan yang berbasis teknologi juga menjadi penunjang untuk kesuksesan bisnis agar lebih akurat dalam mengatur keuangan sehingga dapat menarik minat investor.

Oleh karena itu, perlunya peningkatan ilmu manajemen keuangan serta aplikasi teknologinya bagi usaha kecil, dalam mengembangkan usaha kedepannya. Untuk lebih rincinya, permasalahan dari sisi internal yang dihadapi oleh Kelompok Wirausaha akan dijabarkan pada Tabel 1.

Tabel 1 Permasalahan dari Sisi Internal yang Dihadapi oleh Kelompok Wirausaha

\begin{tabular}{|c|c|}
\hline Kemampuan dan Pengetahuan Manajemen & Bentuk Permasalahan yang Dihadapi \\
\hline $\begin{array}{ll}\text { I. } & \text { Aspek Akuntansi (HPP) }\end{array}$ & $\begin{array}{l}\text { Kebanyakan kelompok Wirausaha Muda ini belum } \\
\text { melakukan pencatatan setiap transaksi dalam bentuk } \\
\text { laporan akuntansi yang baik dan benar. Hal ini } \\
\text { menjadikan mereka sulit mengetahui berapa } \\
\text { keuntungan dan kerugian mereka. }\end{array}$ \\
\hline Aspek Manajemen Keuangan & $\begin{array}{l}\text { Kebanyakan kelompok Wirausaha Muda jarang } \\
\text { menggunakan analisa modal dan investasi terlebih } \\
\text { dahulu dalam menentukan produk apa yang akan } \\
\text { dijual kepada konsumen, penetapan harga produk, } \\
\text { serta trik untuk mengoptimalkan keuangan. Selain itu, } \\
\text { mereka juga belum banyak yang menggunakan } \\
\text { perencanaan keuangan secara terintegrasi } \\
\text { menggunakan sistem informasi yang sangat } \\
\text { dibutuhkan untuk mengelola keuangan yang lebih } \\
\text { baik. }\end{array}$ \\
\hline Aspek Pemasaran & $\begin{array}{l}\text { Kebanyakan kelompok wirausaha belum banyak } \\
\text { mengenal mengenai tekhnologi pemasaran yang } \\
\text { sedang marak pada jaman sekarang dan belum banyak } \\
\text { menggunakan teknologi di bidang pemasaran serta } \\
\text { ketepatan sasaran yang dilakukan oleh para wirausaha. }\end{array}$ \\
\hline IV. Ekonomi Kreatif & $\begin{array}{l}\text { Kebanyakan para wirausaha merasa kekurangan ide } \\
\text { untuk melakukan inovasi dari bahan baku yang sudah } \\
\text { ada ataupun mencari ide/gagasan baru }\end{array}$ \\
\hline
\end{tabular}

Sedangkan hambatan dari sisi eksternalnya yang dihadapi oleh kelompok Wirausaha Muda ini: Kondisi ekonomi yang tidak stabil seperti kenaikan harga bahan pokok, menyebabkan usaha ini mendatangkan keuntungan yang kecil bahkan juga terjadi kerugian, masih banyaknya para pemasok dana baik itu koperasi dan lembaga perbankan yang masih belum percaya untuk memberikan suntikan modal pada usaha ini, terjadinya persaingan yang tidak sehat baik diantara sesama usaha kecil maupun 
dengan usaha menengah, masih banyaknya masyarakat yang tidak percaya akan produk yang dihasilkan dari usaha ini.

Berdasarkan hambatan di atas maka tim PPM Fak. Ekonomi berencana memanfaatkan potensi UMKM yang ada dalam upaya peningkatan kesejahteraan masyarakat melalui program pengabdian pada masyarakat sebagai implementasi tri dharma perguruan tinggi mencanangkan pengabdian pada masyarakat tahun 2019 berupa workshop bagi beberapa kelompok UMKM yang ada di kecamatan Sukajadi.

Pengabdian Pada Masyarakat mempunyai tujuan sebagai berikut: Fasilitasi embrio wirausaha baru pada wilayah binaan / PPM dengan memanfaatkan potensi lokal yang ada, Pemberdayaan Ekonomi mitra melalui kemampuan pemasaran produk UMKM melalui penerapan aplikasi teknologi yang efektif, Fasilitasi peningkatan kemampuan pengelolaan usaha (produksi, keuangan, pemasaran dan SDM), Pemberdayaan ekonomi masyarakat melalui ekonomi kreatif.

\section{METODE}

Metode kegiatan dalam rangka pengabdian pada masyarakat secara umum berbentuk workshop atau pelatihan dan bakti masyarakat yang terdiri dari:
A. Program Workshop

Program workshop yang dilaksanakan adalah:

1) Workshop mengenai Harga Pokok Produksi

2) Workshop mengenai laporan keuangan sederhana

3) Workshop mengenai laporan Pajak

4) Workshop mengenai pemasaran

5) Workshop mengenai ekonomi kreatif

Mitra yang akan diajak kerjasama dalam kegiatan ini adalah Para UMKM yang ada di Kecamatan Sukajadi.

Sementara Kegiatan Bakti Masyarakat yang direncanakan berupa:

1) Pelayanan Kesehatan, berupa pelayanan kesehatan secara gratis atau.

2) Pasar Murah, berupa penjualan bahan sandang pantas pakai dengan harga murah.

\section{HASIL DAN PEMBAHASAN}

Pelaksanaan kegiatan pengabdian pada masyarakat dilaksanakan pada tanggal 11 September 2019. Pelaksanaan workshop bertempat di Universitas Sangga Buana Secara rinci hasil kegiatan sebagai berikut:

\section{Materi 1 Harga Pokok Penjualan}


Memberikan pengetahuan tentang pelatihan bagaimana membuat Harga Pokok Produksi yang di berikan oleh Ibu Henda Hendawati, SE., MM., Wiwin Sukiati, SE., M.Si., Lucy Nurfadilah, SE., MM., Rima Dwijayanty, SE., MM., Wuri

Handayani, SE., M.Si., Yuli Surya

Fauzia Pertami, SE., M.Si., Indri

Gustirani, SE., MM., Surya Ansori, SE., MM., Iyan Sukiman, SE., MM, dengan materi antara lain:

- Memberikan pengetahuan agar dapat mengetahui cara menghitung harga jual yang sesuai dengan pembukuan.

- Memberikan pengetahuan untuk dapat menghitung harga jual agar tidak mengalami kerugian atau mengalami harga yang mahal.

- Memberikan pengetahuan agar bias embedakan antara Biaya Tenaga angsung dengan Biaya Tenaga Kerja Tidak Langsung.

- Segala biaya yang berkaitan dengan pemasaran jasa bisnis, masuk ke komponen komisi penjualan atau biaya marketing. Salah satu contoh konkritnya adalah biaya iklan.

- Perhitungan harga pokok produksi, harga jual dan cash flow, memberikan pemahaman menentukan harga pokok produksi, harga jual dan cash flow.

- Memberikan pelatihan untuk menghitung Harga Pokok Produksi.

- Memberikan tips bagaimana mengontrol keuangan diantaranya: Berinvestasi dengan Baik, Disiplin, membuat atau memiliki perencanaan Keuangan, dan mengontrol kebiasaan.

- Memberikan pelatihan agar dapat memahami bagaimana menghitung Harga Pokok Produksi antara perusahaan jasa dan manufaktur.

- Memberikan pemhaman untuk mengetahui mana yang termasuk komponen COR. 


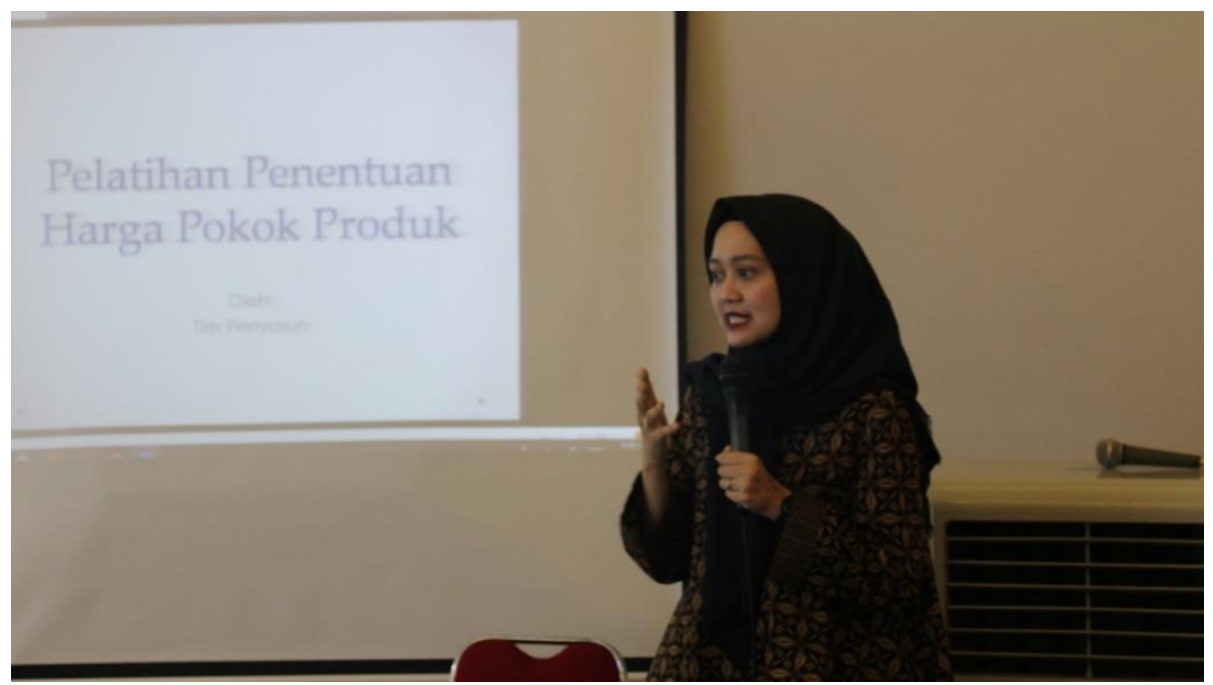

Gambar 1: Penyampaian Materi Pelatihan tentang Harga Pokok Produk

\section{Materi Laporan Keuangan}

\section{Sederhana}

Memberikan pengetahuan tentang pelatihan, maka workshop memberikan pengetahuan tentang Laporan Keuangan yang di berikan oleh Ibu Dr. Erna Garnia, SE., MM., Tahmat, SE., M.Si., Kiki Yuliani, SE., MM., Hilda Purnamawati, SE., M.Si., Dekrita Komarasakti, SE., M.Si., Anita Syafariah, SE., MM., Deden Rizal R, SE., ME., Bambang Rustandi, SE., M.Si., Fitria Lilyana, SE., M.Si., Hadi Ahmad Sukardi, SE., MM. dengan materi antara lain:

- Memberikan pengetahuaan bagaimana cara menghitung laporan keuangan yang sebenarnya.

- Pencatatan dan monitoring setiap kegiatan untuk menetukan ketepatan perencanaan yang telah dibuat.

- Memberkan pengetahuan untuk membuat laporan keuangan yang bias di pahami oleh orange lain.

- Memberikan gambaran bagaimana membuat laporan Keuangan yang baik.

- Laporan keuangan yang sesuai dengan pembukuan.

- Memberikan pengetahuan adar dapat memisahkan anggaran bisnis dan keuangan pribadi.

- Membuat Rencana dan pengembangan usaha

- Mempersiapkan dana darurat

- Pilih vendor/pemasok yang terbaik sebelum membuat perjanjian

- Menghemat pengeluaran bisnis dan belajar akuntansi 
- Untuk melakukan evaluasi rutin arus kas

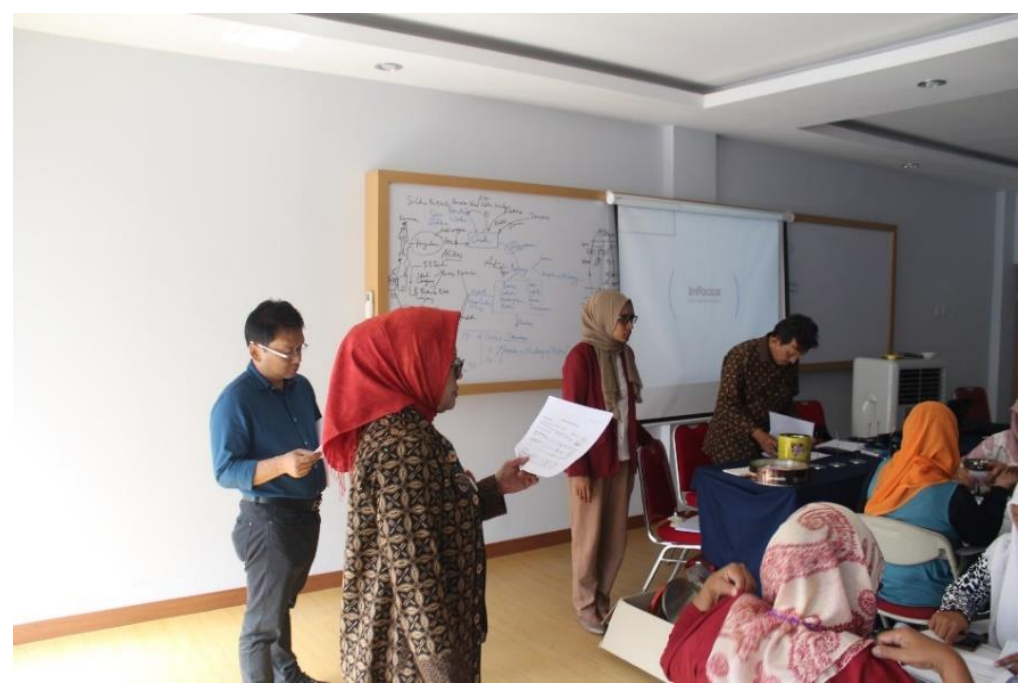

Gambar 2: Penyampaian Materi Pelatihan tentang Laporan Keuangan Sederhana

\section{Materi Laporan Pajak}

Memberikan pengetahuan tentang pelatihan, maka workshop memberikan pengetahuan tentang bagaimana pelaporan Pajak yang di berikan oleh Ibu Hetty Herawati, SE., M.Si., Yuli Nawangsasi, SE., M.Si., Erik Nugraha, SE., M. Akt., Medianto Suryo, SE., M. Akt., Syarif Hidayat, SE., M. Akt., Tevi Leviany, SE., M.Si., Welly Surdjono, SE., M.Si., Sukadwilinda, SE., M.Si. dan Tim dari KPP Pratama Bojonagara dengan materi antara lain:
- Memberikan pengetahuan bagaimana mebuat laporan pajak yang baik.

- Memberikan pengetahuan bahwa pelaporan pajak usaha itu sangat penting, yang bermula dari laporan keuangan yang baik

- Memberikan informasi terkait untuk pelaporan pajak.

- Memberikan pengetahuan bagaimana cara membuat NPWP.

- Pelaporan pajak yang baik. 


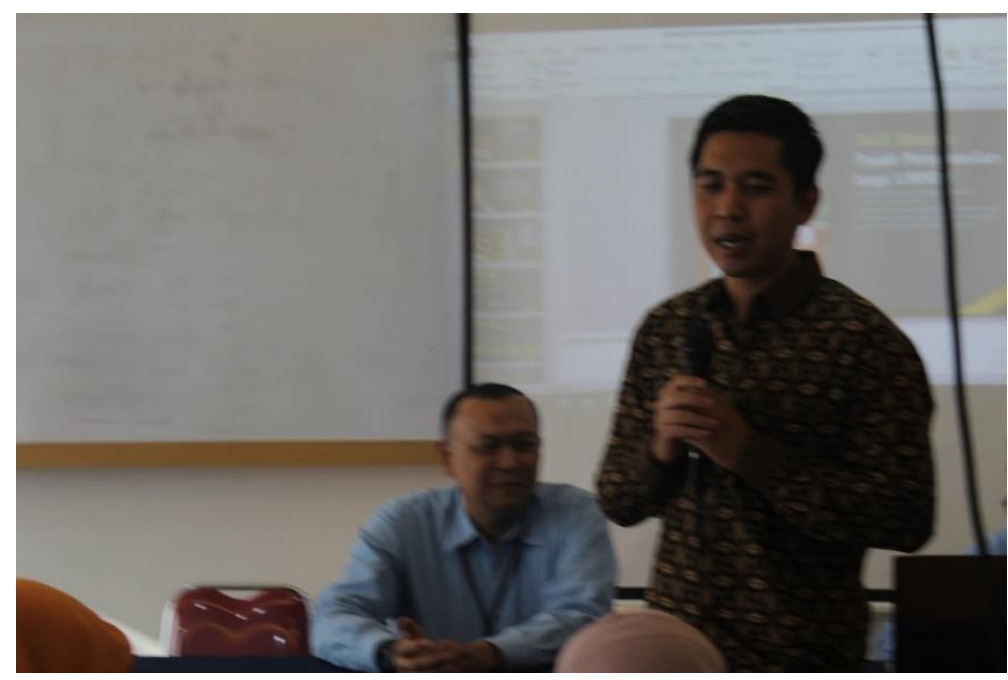

Gambar 3: Penyampaian Materi Pelatihan tentang Laporan Pajak

\section{Materi Pemasaran}

Memberikan pengetahuan tentang pelatihan, maka workshop memberikan pengetahuan tentang bagaimana pelaporan Pajak yang di berikan oleh Ibu Audita Setiawan, SE., MM., Bambang Susanto, SE., M.Si., Dr. Sri Rochani Mulyani, SE., M.Si., Tiktik Sartika, SE., M.Si., Rusmin Nuryadin, SE., M.Si., Ine Aprianti, SE., MM., Sumeidi Kadarisman, SE., MM., Asep Jamaludin, SE., M.Si., Dadang Saeful Hidayat, SE., MM., Ahmad Zulfahmi Ubaidilah, S.Pd., M.Pd. dengan materi antara lain:

- Segmentasi, memberikan pengetahuan dan menentukan profil-profil segmentasi pasar dengan dilihat dari umur, pendapatan dan jenis kelamin.
- Targeting, menentukan target pasar atau sasaran pasar.

- Positioning, menentukan cara produk yang dapat dibedakan melalui atribut yang penting yang dapat membedakan pesaing.

- Memberikan pengetahuan untuk melakukan pemasaran yang baik agar bisa di kenali oleh konsumen.

- Memberikan pengetahuan bahwa teknologi bisa di jadikan pemasarn

- Bagaimana cara memasarkan produk yang baik sehingga dapat menarik dimata konsumen

- Mempelajari pemasaran berbasis online.

- Membuat kemasan yang baik agar dapat laku di pasaran.

- Mempelajari bagaimana membuat nama Brand Image agar konsumen 
mudah menghafal pruduk yang

kita jual.

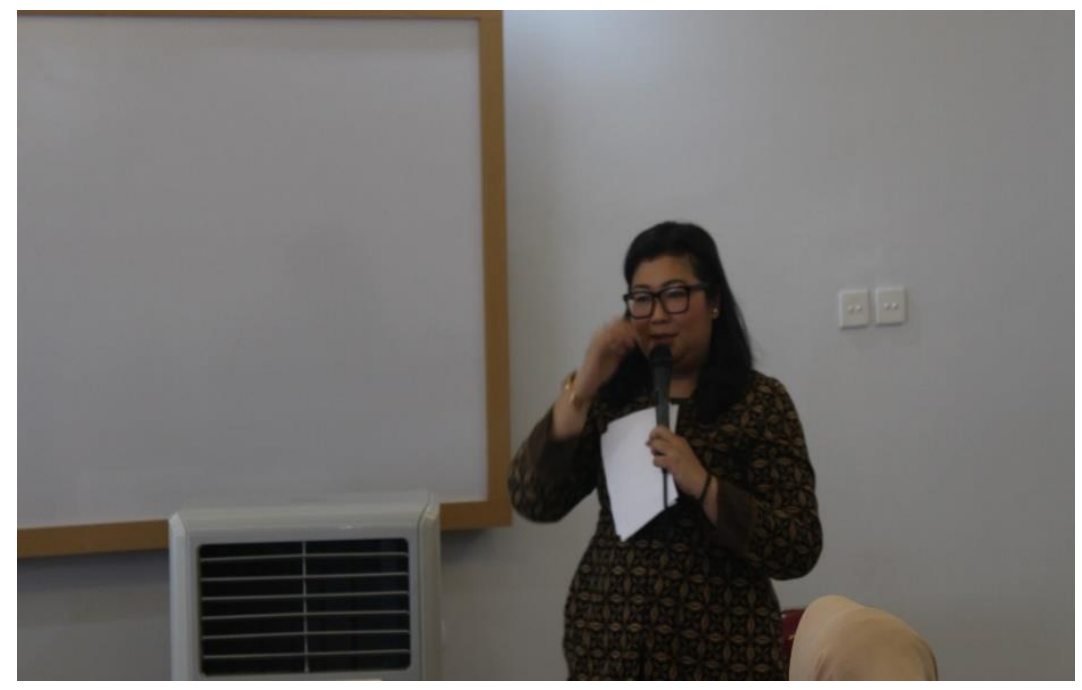

Gambar 4: Penyampaian Materi Pelatihan tentang Laporan Pemasaran

\section{Materi Ekonomi Kreatif}

Memberikan pengetahuan tentang pelatihan, maka workshop memberikan pengetahuan tentang bagaimana pelaporan Pajak yang di berikan oleh Ibu Ae Suaesih, SE., M.Si., Dr. Nenny Hendajany, SE., S.Si., MT., Triyani Hayati, S.PSi., MM., Ae Suaesih, SE., M.Si., Sri Wahyuni, S.Sn., MM., Senny Lusiana, SH., MH., R. Aryanti Ratnawati, SE., M.Si., Louisiani Mansoni Isniyati, SE., MM., Eva Rachmawati, SE., MM., Ninawati, SE., MM. dengan materi antara lain:

- Memberikan pengetahuan bbagaimana melakukan inovasi agar barang tidak terlalu kuno.
- Memberikan pengetahuan untuk membuat bahan sisa menjadi barang yang bisa di jual.

- Terdapat beberapa unsur utama seperti kreativitas, keahlian, dan talenta yang memiliki nilai jual melalui penawaran kreasi intelektual.

- Produk yang dihasilkan (barang dan jasa) memiliki siklus hidup singkat, margin tinggi, beranekaragam, persaingan tinggi, dan dapat ditiru.

- Terdiri atas penyediaan produk kreatif langsung pada pelanggan dan pendukung penciptaan nilai kreatif pada sektor lain yang secara tidak langsung berhubungan dengan pelanggan. 
- Dibutuhkan kerjasama yang baik antara berbagai pihak yang berperan dalam industri kreatif, seperti kaum intelektual, dunia usaha, dan pemerintah.
- Pengembangan industri kreatif tidak terbatas dan dapat diterapkan pada berbagai bidang usaha.

- Konsep creative economy yang dibangun bersifat relatif

- Creative economy berbasis pada ide atau gagasan.

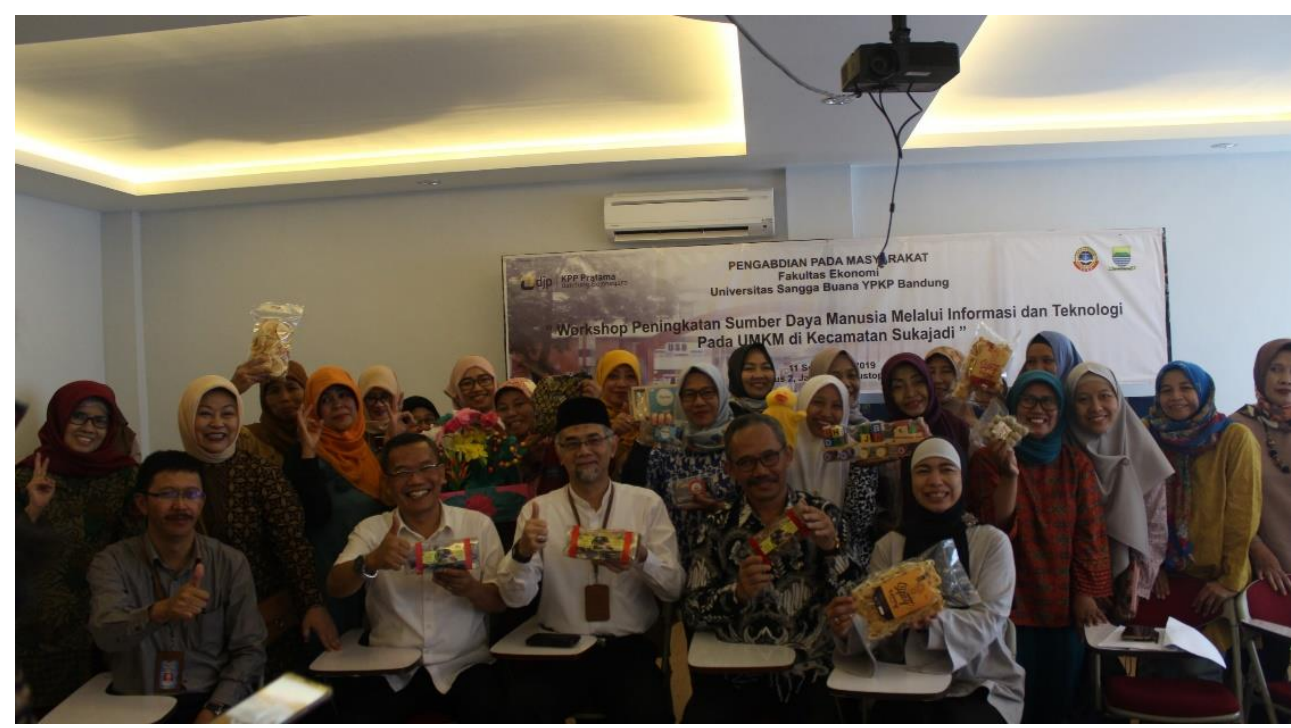

Gambar 5: Penyampaian Materi Pelatihan tentang Ekonomi Kreatif

\section{KESIMPULAN DAN SARAN}

\section{Kesimpulan}

Adapun kesimpulan dari kegiatan ini yaitu:

1) Adanya transfer pengetahuan dari akademisi dan praktisi dalam upaya membantu pengenalan dan pengembangan membina UMKM yang baik.

2) Meningkatkan motivasi kepada masyarakat untuk bisa lebih maju dengan sumber daya yang ada dengan melakukan inovasi-inovasi.

3) Adanya transfer pengetahuan dari akademisi dan atau praktisi dalam upaya membantu pemecahan permasalahan dalam membangun UMKM yang baru bergerak, bahkan yang sudah berjalan untuk dapat menciptakan wirausaha yang baru yang kompeten dengan keahlian jenis usahanya. Permasalahan dalam mengolah bahan baku menjadi nilai jual yang tinggi.

4) Adanya transfer ilmu untuk para UMKM bagaimana cara membuat laporan yang baik bahkan bisa di pahami oleh orang lain. 
5) Mengingatkan untuk para UMKM bahkan bagi para UMKM yang baru

\section{Saran}

Dengan workshop dapat menjadikan bekal yang mumpuni untuk para UMKM dapat mengaplikasikannya langsung untuk melakukan usaha dengan berkelanjutan namun terdapat beberapa kendala yang masih harus dipecahkan, maka direncanakan akan ada tindak lanjut dari kegiatan PPM, antara lain:

1. Tindak lanjut produksi secara langsung

2. Pembinaan langsung untuk dapat dibuat organisasi wirausaha

3. Menghasilkan wirausaha UMKM kelompok berdiri untuk wajib melaporkan pajak.

\section{DAFTAR PUSTAKA}

[1] https://solusiukm.com/gimananentuin-harga-pokok-penjualanbagi-umkm/

[2] https://www.jurnal.id/id/ blog/cara-mudah-membuatlaporan-keuangan-sederhana-bagiukm/

[3] https://klikpajak.id/blog/tipspajak/aspek-perpajakan-umkm/

[4] https://www.jurnal.id/ $\mathrm{id} / \mathrm{blog} / 2018$-strategi-pemasaranyang-efektif-untuk-ukm/

[5] https://ekonomi.bisnis. com/read/20191213/12/1181057/ pengembangan-umkm-pemasarandan-promosi-masih-jadi-kendala

[6] https://www.neliti.com/ publications/19599/pengembanga n-usaha-mikro-kecil-danmenengah-umkm-berbasisekonomi-kreatif-di-kot 